\title{
Grasshopper populations respond similarly to multiple moderate intensity livestock grazing treatments
}

\author{
DAVID H. BRANSON'
}

1 United States Department of Agriculture, Agricultural Research Service, 1500 N. Central Avenue, Sidney, MT 59270, USA.

Corresponding author: David H. Branson (Dave.branson@usda.gov)

Academic editor: Maria-Marta Cigliano | Received 30 September 2019 | Accepted 21 November 2019 | Published 14 May 2020

http://zoobank.org/BB3F6B96-BA16-47F2-96F0-103FA9FE87B8

Citation: Branson DH (2020) Grasshopper populations respond similarly to multiple moderate intensity livestock grazing treatments. Journal of Orthoptera Research 29(1): 67-69. https://doi.org/10.3897/jor.29.46966

\begin{abstract}
Livestock grazing frequently affects grasshopper populations, but no prior studies have simultaneously examined a wide range of moderate intensity livestock grazing treatments in the Northern Great Plains. Grasshopper densities varied significantly between years, but five moderate grazing treatments, including both rotational and continuous grazing treatments, did not differentially affect grasshopper densities or species composition. Grasshopper populations appear resilient to different types of moderate grazing at this Northern Great Plains mixed-grass prairie site.
\end{abstract}

\section{Keywords}

Acrididae, continuous grazing, grasshopper density, Great Plains, mixed prairie, rangeland, rotational grazing

\section{Introduction}

Grasshoppers are frequently the most abundant herbivore in North American grasslands, often consuming more vegetation than livestock during outbreaks and can be in competition with livestock (Branson et al. 2006, Branson and Haferkamp 2014). Grasshopper responses to livestock grazing vary across western U.S. ecosystems (Branson et al. 2006). Livestock grazing can reduce food availability for grasshoppers, modify plant species composition, and impact habitat structure (Fielding and Brusven 1996, Onsager 2000, Branson et al. 2006, O'Neill et al. 2010, LeGall et al. 2019). Species specific responses to livestock grazing are common, with many pest grasshoppers in the Northern Great Plains thriving in open microhabitats (Onsager 2000, Joern 2004, 2005, Joern and Laws 2013).

Relatively few studies in the Northern Great Plains have assessed how grazing intensity or treatments with a similar grazing intensity affect grasshopper populations (Onsager 2000, Branson and Sword 2010, Branson and Haferkamp 2014, Branson and Vermeire 2016). Certain moderate intensity livestock grazing systems appear to have potential for use as a vegetation habitat manipulation tool in managing grasshoppers, with continuous and twice-over rotational livestock management systems differentially affecting grasshopper populations in the Northern Great Plains (Onsager 2000, Branson et al. 2006). No previous studies have examined impacts of many moderate grazing intensity treatments on grasshopper populations in the Northern Great Plains. The objective of this study was to examine grasshopper density and community composition responses to five moderate intensity livestock grazing treatments, as part of a study examining vegetation responses to grazing (Vermeire et al. 2008).

\section{Materials and methods}

The experiment was conducted on the USDA, ARS, Fort Keogh Livestock and Range Research Laboratory near Miles City, Montana, USA $\left(46^{\circ} 19^{\prime} 25^{\prime \prime} \mathrm{N}, 105^{\circ} 49^{\prime} 36^{\prime \prime} \mathrm{W}\right)$. The study site and experimental design are fully described in Vermeire et al. (2008). Vegetative biomass was dominated by perennial grasses, with blue gramaneedlegrass-wheatgrass the dominant rangeland vegetation type (Vermeire et al. 2008). Five grazing treatments with an identical moderate cattle grazing rate of 28.8 animal unit days ha ${ }^{-1}$ year ${ }^{-1}$ were compared. These covered a wide range of livestock grazing management approaches used in the region of the study site. Technical details of the grazing treatments are fully described in Vermeire et al. (2008). The five grazing treatments were: season-long continuous livestock grazing; high-intensity, low-frequency grazing with a 24day graze followed by a 706-day rest period; short-duration grazing with a three-day graze followed by a 42 -day rest period; three-pasture winter rotation grazing; and three-pasture summer, twice-over rotation grazing with 15- and 30-day graze periods (Vermeire et al. 2008). Treatments were randomly assigned to two replicate 6.1 ha pastures. Vegetation responses including biomass and composition were measured (Vermeire et al. 2008). Grazing treatments were initiated in 1997 and grasshopper sampling occurred from 1997 to 2000. Grasshopper densities were assessed between June and early September each year, with ten samples in 1997 and 1998, eight in 1999 , and four in 2000. In each replicate pasture, 40 rings of $0.1 \mathrm{~m}^{2}$ were permanently placed in four transects located approximately 5-10 $\mathrm{m}$ from each other, and the number of grasshoppers flushed from each ring were counted. Random sweep net samples were collected to assess grasshopper species composition on July $13^{\text {th }}$ and $23^{\text {rd }}, 1999$, and July $12^{\text {th }}$ and August $1^{\text {st }}$ of 2000.

As grasshoppers in the study area are univoltine and sampling efforts varied, density samples were averaged within each year. 
Treatment differences in densities over four years were assessed using a repeated-measures ANOVA model. A permutational distance-based MANOVA (PERMANOVA), using a Bray-Curtis (Sorensen) distance measure, was used to assess treatment differences in grasshopper community composition (Anderson 2001, 2017). Species that occurred in only one plot were deleted prior to analysis (McCune and Grace 2002). As the number of species present in at least two plots varied between years, community composition was analyzed separately for 1999 and 2000. Due to the low replication, a significance level of 0.1 was deemed appropriate $a$ priori. Systat 13 was used for the repeated measures analysis and PC-ORD 6.22 was used for PERMANOVA analyses.

\section{Results and discussion}

Grasshoppers were generally abundant during the study, with relatively stable densities during the last three years (Fig. 1). The grasshopper community was dominated by two Gomphocerinae (slantfaced) species, Opeia obscura and Ageneotettix deorum, and two Melanoplinae (spurthroated) species, Phoetaliotes nebrascensis and Melanoplus sanguinipes (Table 1). Three of these species feed primarily on grasses and sedges, while M. sanguinipes is a generalist, mixed grass and forb feeder. Community composition did not differ between grazing treatments in either 1999 or 2000 (Table 2). There were also no significant grasshopper density differences between the moderate grazing rate treatments, although densities differed between years (Table 2). Study replication was low, but there was no indication that moderate grazing treatments differentially affected grasshoppers as treatments explained very little of the variation in densities (Table 2). The lack of density and species composition differences between moderate intensity grazing treatments parallels the vegetation results of Vermeire et al. (2008). Standing vegetation biomass and functional composition were largely resistant to moderate grazing systems, with similar results between rotational and continuous grazing strategies (Vermeire et al. 2008).

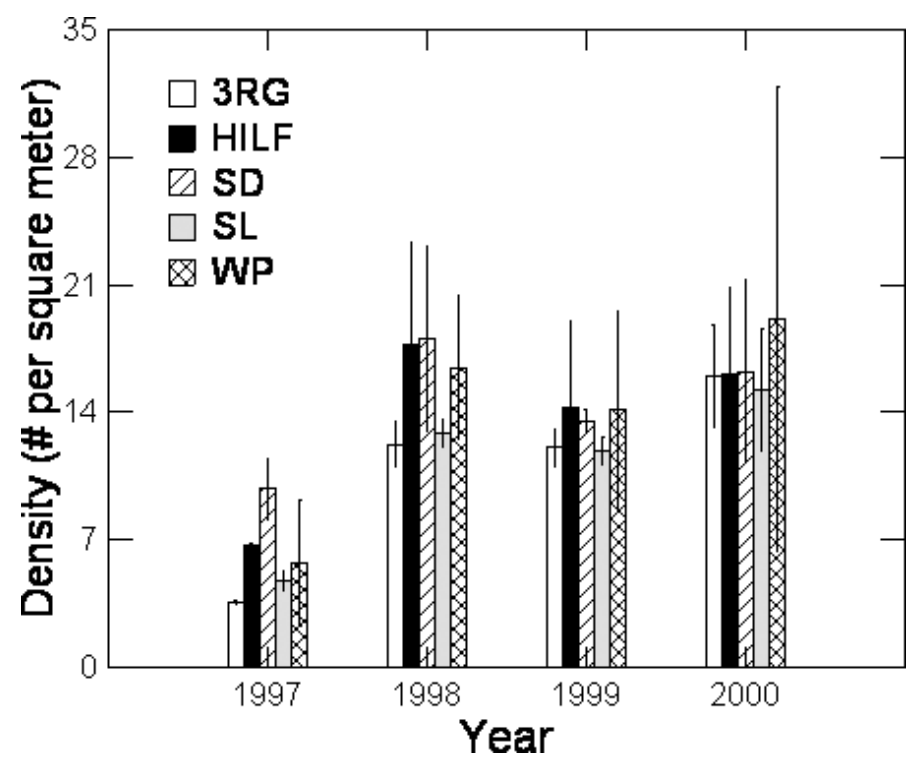

Fig. 1. Average grasshopper density (\# per $\mathrm{m}^{2}$, mean $\pm \mathrm{SE}$ ) from 1997 through 2000 for each treatment. (3RG: three-pasture, twiceover rotational grazing; HILF: high-intensity low-frequency grazing; SD: short-duration grazing; SL: season-long continuous grazing; and WP: three-pasture winter rotation).
Table 1. Average grasshopper species composition from sweep net samples at the site in 1999.

\begin{tabular}{lc}
\hline \multicolumn{1}{c}{ Species } & \% of total caught \\
\hline Opeia obscura & 25.3 \\
Ageneotettix deorum & 25.1 \\
Phoetaliotes nebrascensis & 22.1 \\
Melanoplus sanguinipes & 16.9 \\
Trachyrhachys kiowa & 3.1 \\
Eritettix simplex & 1.7 \\
Encoptolophis costalis & 1.3 \\
Mermiria bivittata & 1.1 \\
\hline
\end{tabular}

Table 2. Statistical results from A. Repeated measures ANOVA model examining grazing treatment effects on average grasshopper density across all years; $\mathrm{B}$. Permutational multivariate analysis of variance examining treatment effects on grasshopper community composition in 1999 with analysis based on Bray-Curtis dissimilarities; and C. Permutational multivariate analysis of variance examining treatment effects on grasshopper community composition in 2000 with analysis based on Bray-Curtis dissimilarities.

\begin{tabular}{lccccc}
\hline & Factor & df & SS & F & P \\
\hline A. & Year & 3 & 660.881 & 39.554 & 0.000 \\
& Year*Graze & 12 & 48.661 & 0.728 & 0.707 \\
B. & Error & 15 & 83.543 & & \\
& Graze & 4 & 0.360 & 1.277 & 0.280 \\
& Residual & 5 & 0.353 & & \\
C. & Total & 9 & 0.713 & & \\
& Graze & 4 & 0.338 & 1.319 & 0.319 \\
& Residual & 5 & 0.321 & & \\
\hline
\end{tabular}

The season-long continuous and three-pasture, twice-over summer rotation grazing treatments in this study were similar to treatments shown to impact grasshopper microhabitat availability and developmental rates in a study in western North Dakota, USA (Onsager 2000). Grasshopper densities in that study averaged six times higher under continuous grazing compared to twice-over rotational grazing during a two-year period with outbreak densities, which was hypothesized to result from increased ground cover from grass tillering and reduced habitat quality for grasshoppers in the rotational grazing system. In contrast to the results in North Dakota, most replicate pastures in this study had abundant bare ground and low vegetation ground cover, which would reduce the potential impacts of grass tillering. In addition, the below-average spring precipitation observed during three of the four study years likely constrained vegetation responses, as plant biomass production in the study area is closely linked to April and May precipitation (Vermeire et al. 2008). Branson and Sword (2010) also examined the impact of rotational versus continual grazing and found relatively weak effects of grazing during a five-year study when grasshopper densities were low. The results of this study conducted during a period of high grasshopper densities, combined with the results of Branson and Sword (2010), indicate that grasshopper populations may commonly be resilient to moderate grazing in the Northern Great Plains. Given the variable results between the three studies to date, additional experiments examining how grasshoppers respond to differing moderate intensity livestock grazing treatments are needed. 


\section{Acknowledgements}

Jerry Onsager, Jeff Holmes, Sarah Bucklin-Comiskey, and Mitch Faulkner assisted in field work.

\section{References}

Anderson MJ (2001) A new method for non-parametric multivariate analysis of variance. Austral Ecology 26: 32-46. https://doi.org/10.1111 /j.1442-9993.2001.01070.pp.x

Anderson MJ (2017) Permutational Multivariate Analysis of Variance (PERMANOVA). In: Balakrishnan N, Colton T, Everitt B, Piegorsch W, Ruggeri F, Teugels JL (Eds) Wiley StatsRef: Statistics Reference Online. https://doi.org/10.1002/9781118445112.stat07841

Branson DH, Haferkamp MA (2014) Insect herbivory and vertebrate grazing impact food limitation and grasshopper populations during a severe outbreak. Ecological Entomology 39: 371-381. https://doi. org/10.1111/een.12114

Branson DH, Joern A, Sword GA (2006) Sustainable management of insect herbivores in grassland ecosystems: New perspectives in grasshopper control. Bioscience 56: 743-755. https://doi.org/10.1641/00063568(2006)56[743:SMOIHI]2.0.CO;2

Branson DH, Sword GA (2010) An experimental analysis of grasshopper community responses to fire and livestock grazing in a northern mixed-grass prairie. Environmental Entomology 39: 1441-1446. https://doi.org/10.1603/EN09378

Branson DH, Vermeire LT (2016) Grasshopper responses to fire and postfire grazing in the Northern Great Plains vary among species. Rangeland Ecology and Management 69: 144-149. https://doi.org/10.1016/j. rama.2015.10.005
Fielding DJ, Brusven MA (1996) Livestock grazing and grasshoppers: An interregional perspective. University of Idaho College of Agriculture Bulletin 786: 1-12.

Joern A (2004) Variation in grasshopper (Acrididae) densities in response to fire frequency and bison grazing in tallgrass prairie. Environmental Entomology 33: 1617-1625. https://doi.org/10.1603/0046225X-33.6.1617

Joern A (2005) Disturbance by fire frequency and bison grazing modulate grasshopper assemblages in tallgrass prairie. Ecology 86: 861-873. https://doi.org/10.1890/04-0135

Joern A, Laws AN (2013) Ecological mechanisms underlying arthropod species diversity in grasslands. Annual Review of Entomology 58: 19-36. https://doi.org/10.1146/annurev-ento-120811-153540

Le Gall M, Overson R, Cease A (2019) A global review on locusts (Orthoptera: Acrididae) and their interactions with livestock grazing practices. Frontiers in Ecology and Evolution 7: 1-263. https://doi. org/10.3389/fevo.2019.00263

McCune B, Grace JB (2002) Analysis of Ecological Communities. MJM Software Design, Gleneden Beach.

O'Neill KM, Olson BE, Wallander R, Rolston MG, Seibert CE (2010) Effects of livestock grazing on grasshopper abundance on a native rangeland in Montana. Environmental Entomology 39: 775-786. https://doi. org/10.1603/EN09173

Onsager JA (2000) Suppression of grasshoppers in the Great Plains through grazing management. Journal of Range Management 53: 592-602. https://doi.org/10.2307/4003152

Vermeire LT, Heitschmidt RK, Haferkamp MR (2008) Vegetation response to seven grazing treatments in the Northern Great Plains. Agriculture, Ecosystems and Environment 125: 111-119. https://doi.org/10.1016/j. agee.2007.12.003 